\title{
Hydrolysis of 2',3'-O-methyleneadenos-5'-yl
}

\author{
$\operatorname{bis}\left(2^{\prime}, 5^{\prime}\right.$-di-O-methylurid-3'-yl) phosphate, a
}

\author{
sugar $O$-alkylated trinucleoside $3^{\prime}, 3^{\prime}, 5^{\prime}-$
}

monophosphate: implications for the mechanism

of large ribozymes

\author{
Tuomas Lönnberg ${ }^{*}$ and Satu Mikkola \\ Department of Chemistry, University of Turku, Vatselankatu 2, FIN-20014 Turku,
}

Finland

tuanlo@utu.fi

Supporting Information

Contents

S1 General experimental information

S2 - S10 $\quad{ }^{13} \mathrm{C}$ NMR spectra of compounds $9,4,3,10,1,5,6,2 a$ and $2 \mathrm{~b}$

General. The ${ }^{1} \mathrm{H}$ NMR chemical shifts (at $300 \mathrm{~K}$ ) were referred to internal TMS and the

${ }^{31} \mathrm{P}$ NMR shifts $(162 \mathrm{MHz}, 300 \mathrm{~K})$ to external orthophosphoric acid. 


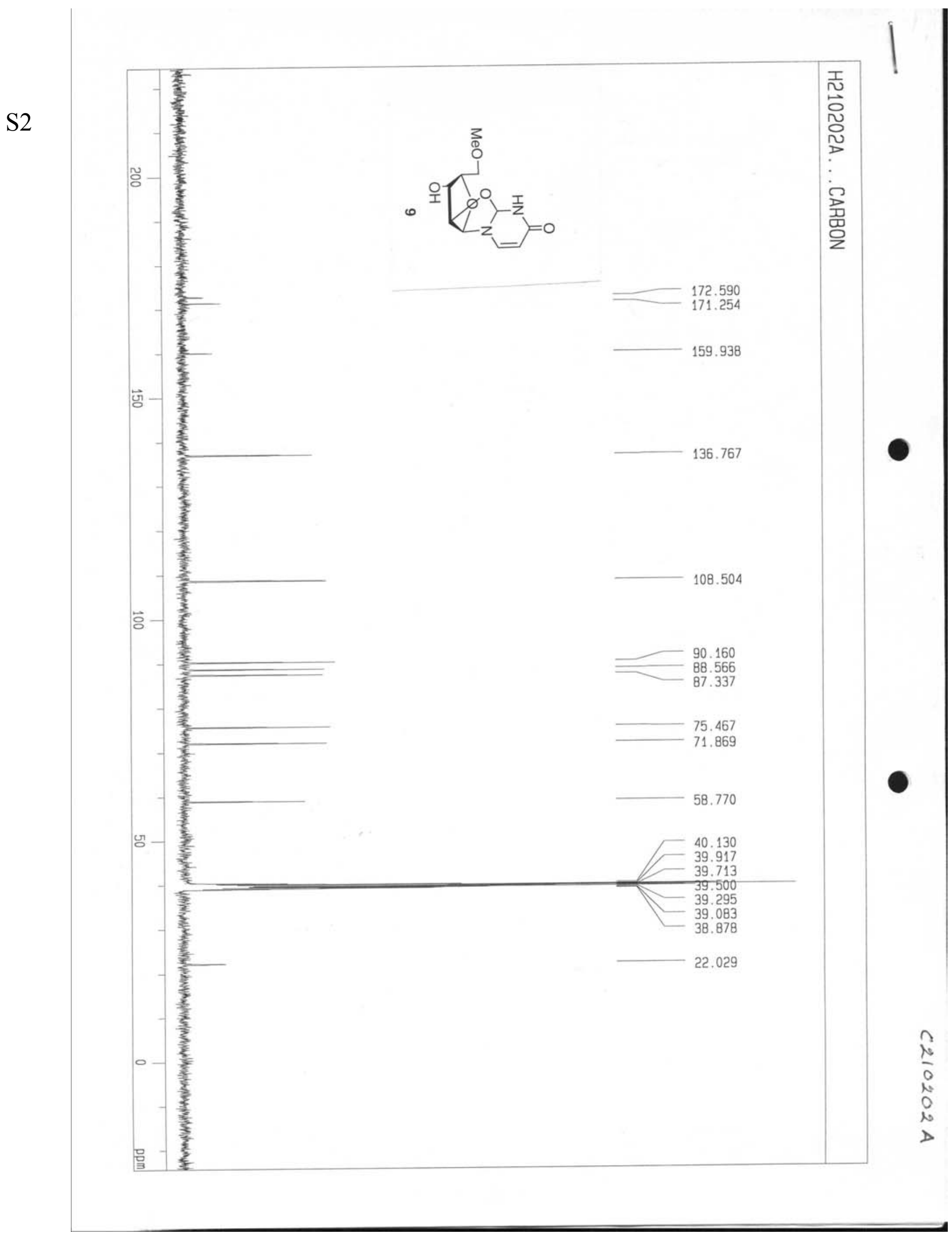




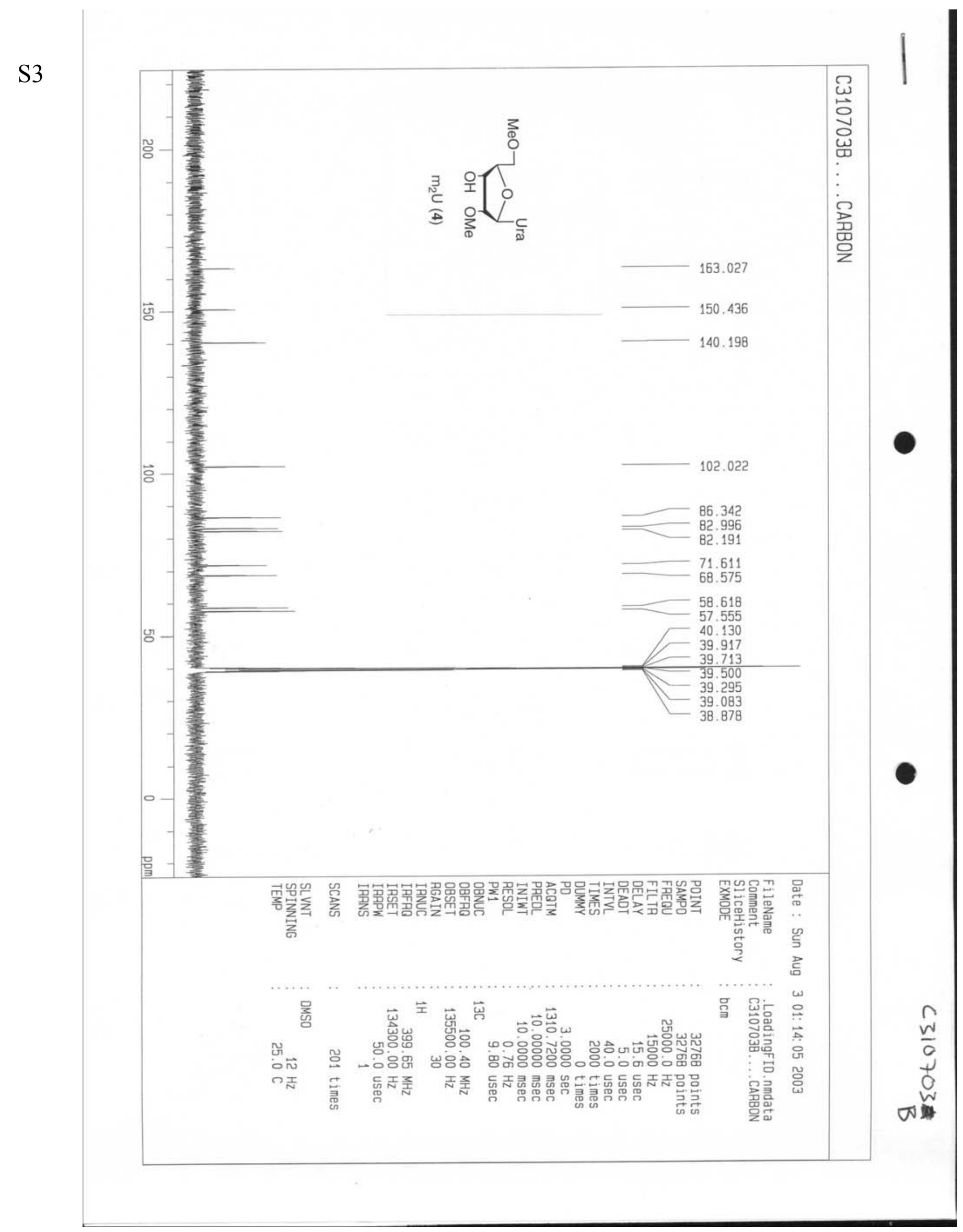



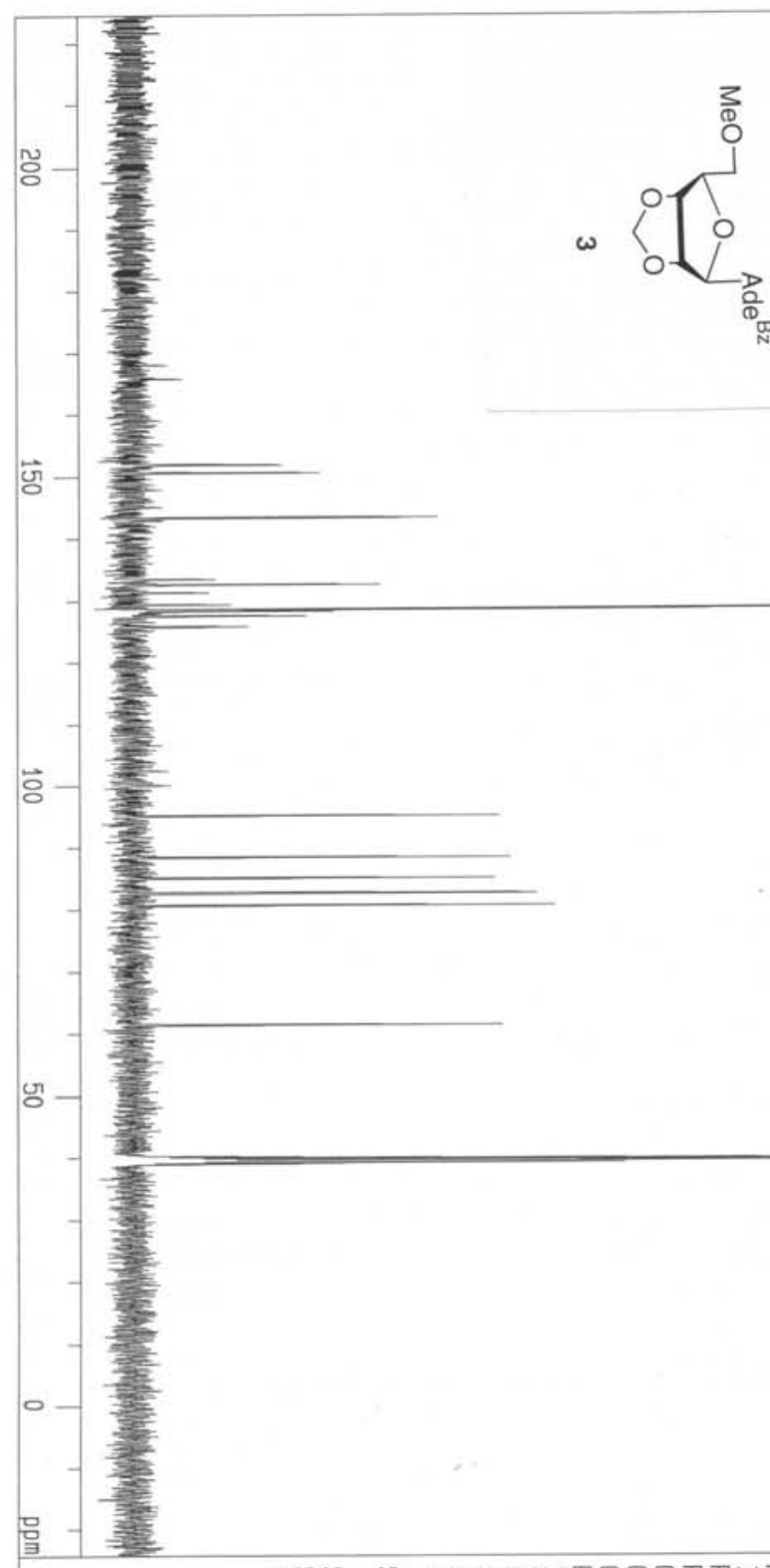

95.124

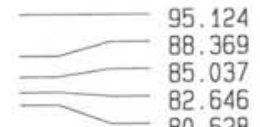

85.037

80.628

61.434

40.130

39.917

39.713

39.295

39.083

38.878

亘计热

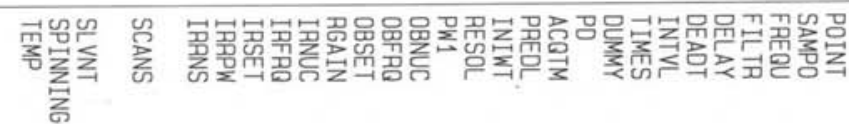

睪要

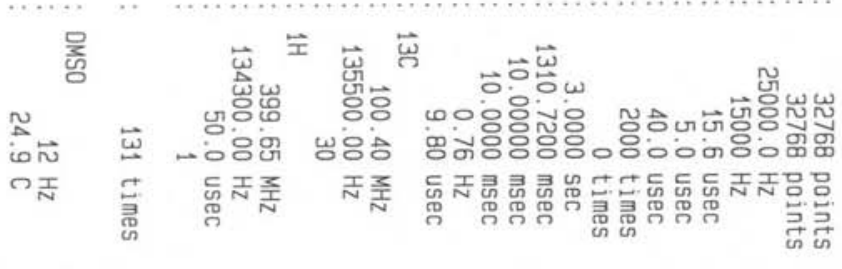

뭌

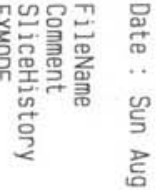

…... w

空

峲

宫

䇏言

w 


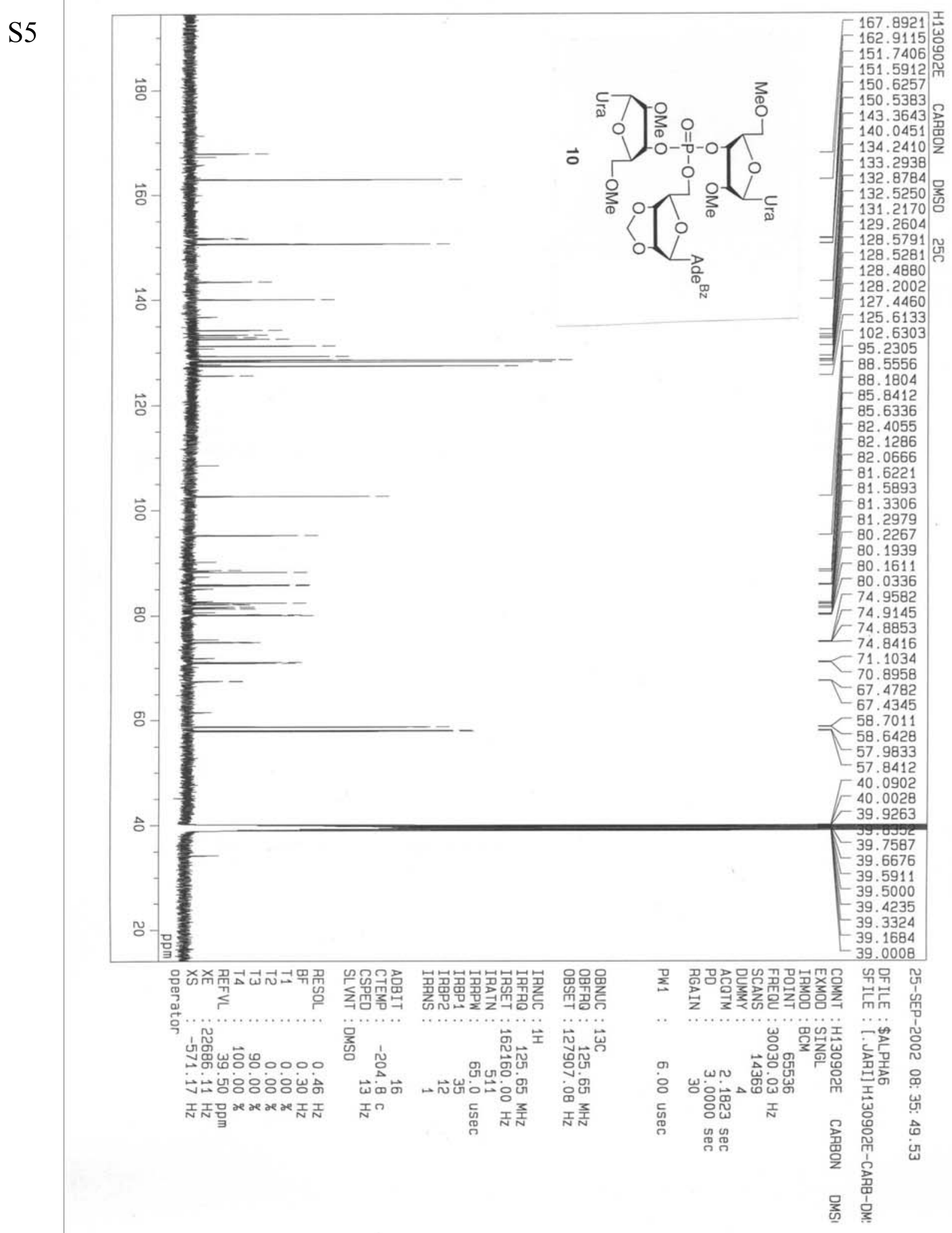




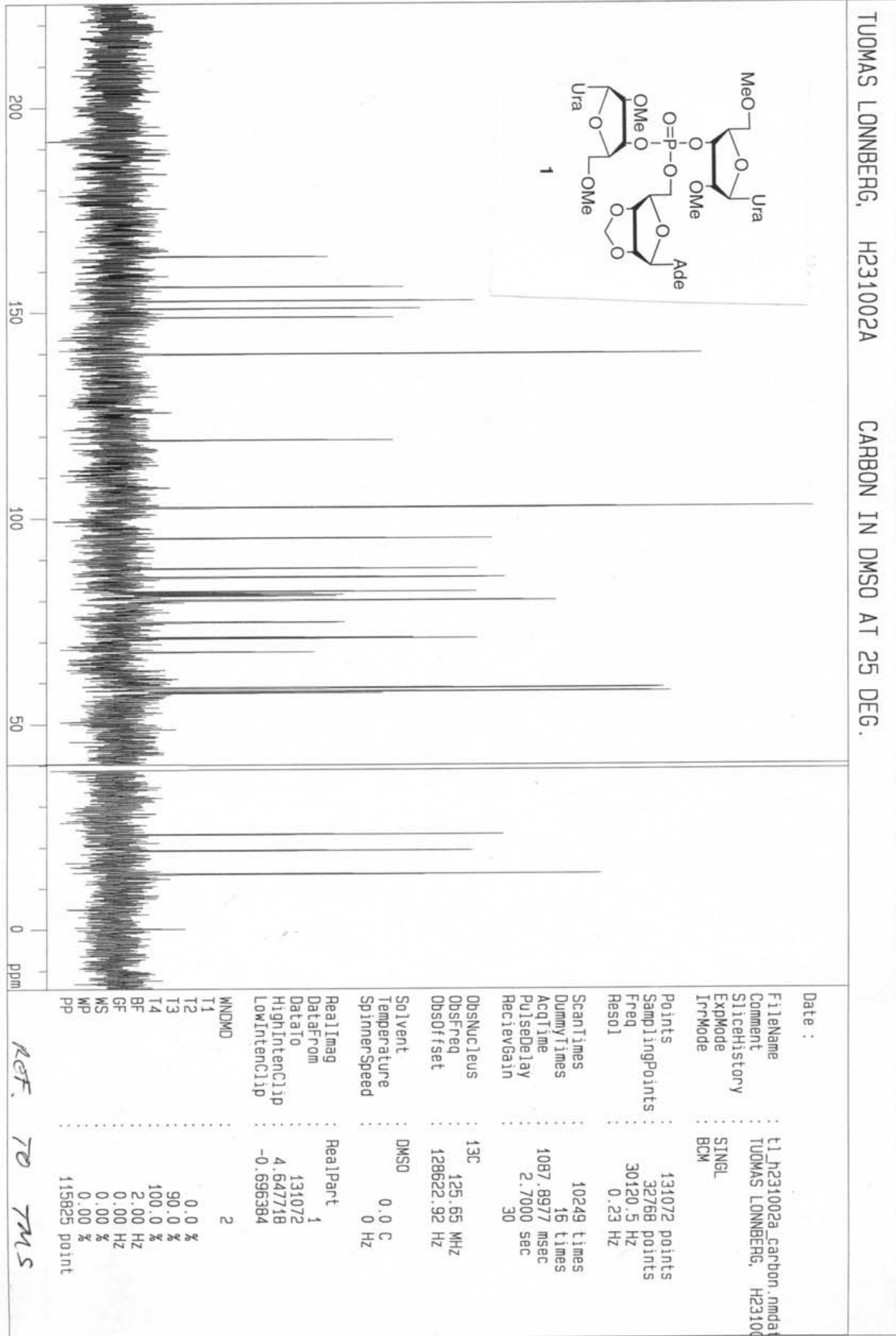




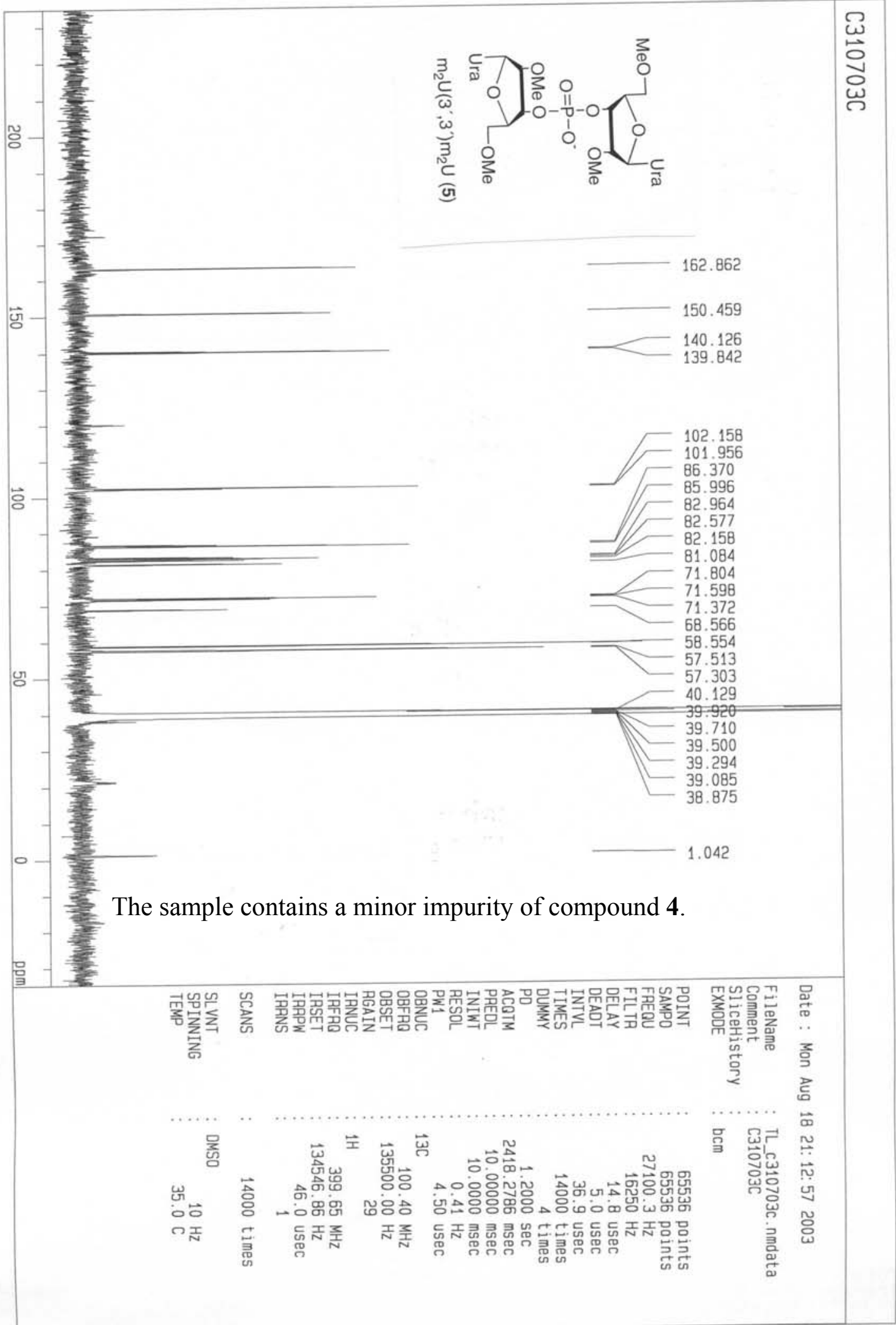

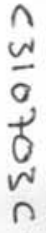




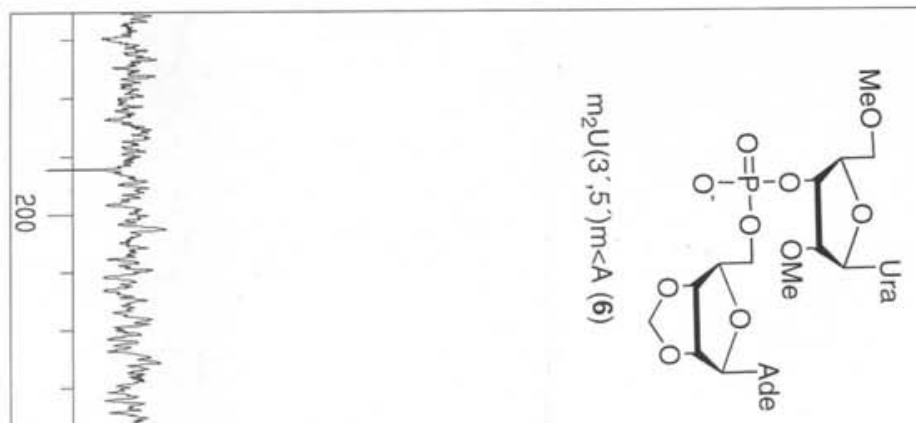

$\stackrel{\leftrightarrow}{\leftrightarrow}$
$\stackrel{0}{0}$
$\stackrel{్}{0}$

방
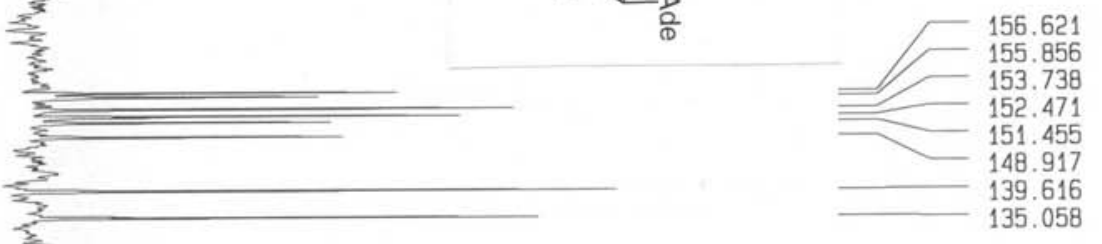

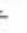

$\frac{2}{\frac{3}{x}}$

$\overrightarrow{8}$

$-$

率

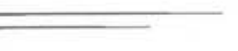

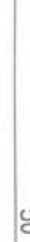

(2)

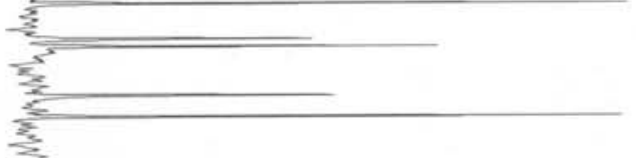

당-

产

?

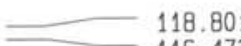

116.473

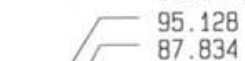

87.834
$-\quad 85.683$

- 84.350

84.947
82.957

ㄹ․ 12.553

$\begin{array}{r}-\quad 74.659 \\ \hline\end{array}$

$-73.346$

64.942

61.277

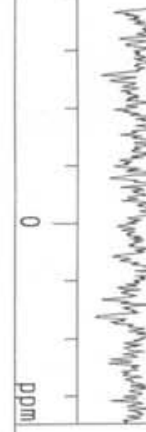

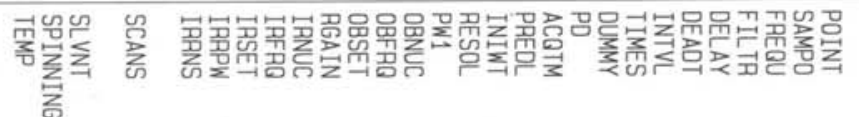

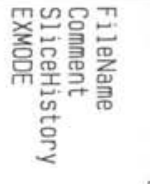

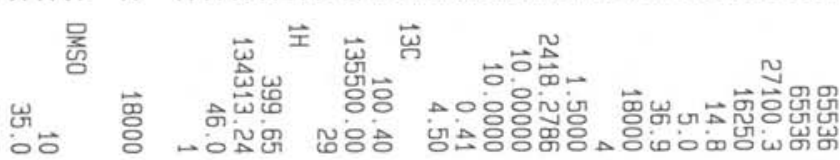

ก $\frac{\text { T }}{2}$

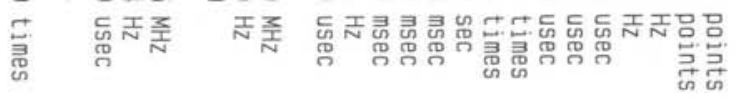




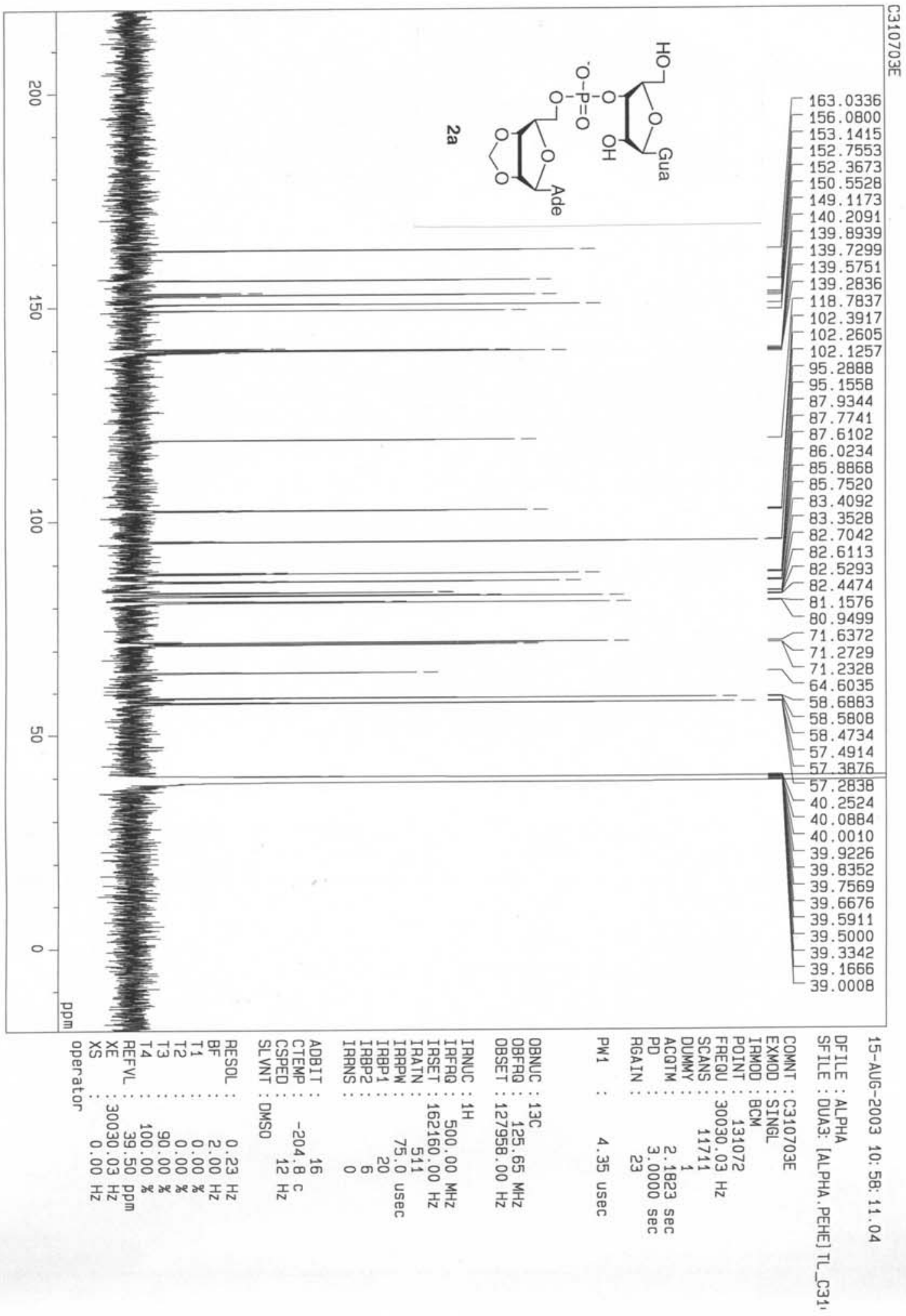




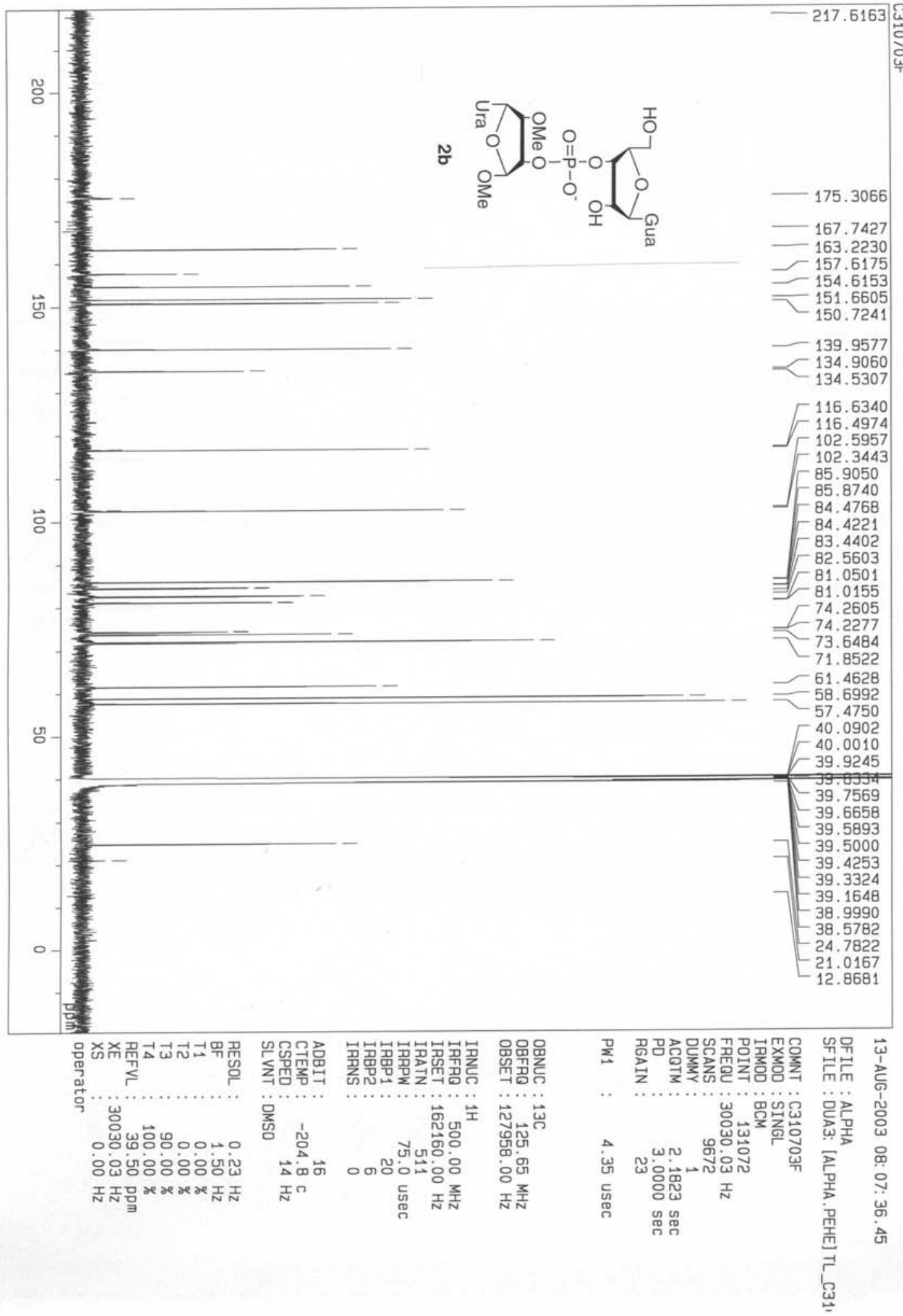

$n$
$w$
$\sigma$
+
0
$w$
$w$
$\pi_{1}$ 